\title{
EL ALFABETO DE LA TERREDAD: \\ ESTUDIO DE LA POÉTICA EN LA OBRA \\ DE EUGENIO MONTEJO
}

\author{
POR \\ Arturo Gutiérrez Plaza \\ Fundación Biblioteca Ayacucho
}

\section{INTRODUCCIÓN}

Al hacer una lectura global de la obra poética de Eugenio Montejo ${ }^{1}$ encontramos un conjunto de elementos que nos permiten apreciar una voz que ha sido capaz de construir un espacio singular dentro de la poesía venezolana y continental. Las siguientes, son algunas de las interrogantes que surgen de esta lectura. ¿Qué elementos hacen de ésta una obra unitaria? ¿Cuál es el conjunto de rasgos que caracterizan de manera específica esta poesía y cuáles sus consecuencias? ¿Qué constantes encontramos al leer cualquier poema de Montejo? La búsqueda de algunas respuestas a las interrogantes planteadas - respuestas que nos acercarán a la definición de una poética - es lo que se intenta desarrollar, sucintamente, en este trabajo.

Para ello, se abordarán tan sólo cuatro aspectos particularmente relevantes de su obra: la función del símbolo; la relación entre poeta, poema y modernidad; la noción de la poesía como espacio religioso; y por último los rasgos heteronímicos de su escritura. Con esto, no se intenta excluir ni negar la importancia que otros tópicos tienen en el conjunto de esta obra. Lo que se busca es definir algunos de los componentes determinantes de la poética montejiana.

\footnotetext{
${ }^{1}$ Eugenio Montejo (Caracas, 1938). Ha publicado los siguientes libros de poesía: Humano Paraíso (Valencia: Impresiones Clima, 1959); Élegos (Caracas: Editorial Arte, 1967); Muerte y Memoria (Caracas: Editorial Arte, 1972); Algunas Palabras (Caracas: Monte Ávila, 1976); Terredad (Caracas: Monte Ávila, 1978); Trópico Absoluto (Caracas: Fundarte, 1982); O poeta sem rio/El poeta sin rio (Edición bilingüe portugués-español) (Porto Alegre: Editora Movimento \& Carlos Tortolero Editor, 1985); Alfabeto del Mundo (Barcelona: Editorial Laia, 1986) (existe una edición ampliada y revisada de esta antología en México: Fondo de Cultura Económica, 1988) y Adiós al siglo XX (Caracas: Ediciones Aymaría, 1992). Además, el autor ha publicado dos colecciones de ensayos: La ventana oblicua (Valencia: Ediciones de la Universidad de Carabobo, 1974) y El taller blanco (Caracas: Fundarte, 1983). Asímismo posee dos volúmenes de escritura heteronímica: El cuaderno de Blas Coll (Caracas: Fundarte, 1981) (edición ampliada y revisada en Caracas: Alfadil, 1983) y Guitarra del horizonte (Caracas: Alfadil, 1991).
} 


\section{A. El universo SIMBólico}

Todo poeta, en tanto hacedor de un lenguaje, es constructor de un universo simbólico. Ello supone, por supuesto, mucho más que las derivaciones propias del uso de un determinado sistema lingüístico. Se trata, más bien, de la construcción consciente y constante de un cúmulo de referencias estrechamente unidas, que se nutren recíprocamente en toda la obra.

Pedro Lastra, al estudiar la poesía de Montejo, ha señalado con relación a esto dos aspectos de significativa importancia. Por una parte, habla del "signo valorizado" como un elemento presente en la poesía de Montejo. Al respecto, apunta: "los símbolos productores de sentido en un poema específico se proyectan de otro modo cuando son leídos en un proceso, se valorizan mediante y gracias a las alianzas que entabla esa comunidad textual", 2 y por la otra, menciona la "práctica de las variaciones" y la "intertextualidad refleja", subrayando ésta como "una actividad generadora de significantes a partir de otros significantes" (Lastra 212) previamente establecidos por la misma obra.

De esto se desprende, tácitamente, una suerte de complicidad o pacto entre el autor y el lector. Así, tras una lectura diacrónica de la obra, se advierten progresivamente los distintos elementos que han ido adquiriendo espesor significativo en el proceso constructivo del conjunto. Un ejemplo de ello, entre muchos otros, lo encontramos en el poema "Album de familia" (Alfabeto del Mundo). Allí, distintos personajes, conocidos por el lector de Montejo (la tía Adela y el hermano Ricardo, que aparecen por vez primera en Élegos) son mencionados nuevamente:

\section{Ésta que asoma al fondo era tía Adela, maga del mundo y viva en tantos tiempos que hasta hoy no sé si existe o si no existe.}

El rey Ricardo se ve mucho más joven que su muerte. Y acaso así alla sido ...

Lo mismo ocurre con hechos aludidos en poemas anteriores como la terrible peste, que diezmó la población de Güigue a comienzos de siglo (“Güigue 1918”, Terredad). En "Album de familia", podemos leer:

Luis, el letrado, se fue pronto

el año de la peste. Dejó cartas, postales,

el mapa de una vaga inocencia.

De esta manera, muchos referentes, al ser "descubiertos" en una lectura que toma en cuenta el conjunto de la obra, reaparecen cargados de connotaciones, producto del diálogo establecido entre el poeta y el lector.

\footnotetext{
${ }^{2}$ Pedro Lastra, "El pan y las palabras: poesía de Eugenio Montejo", Inti 18-19 (Revista de literatura hispánica) (Providence, Rhode Island, otono 1983-primavera 1984) 211.
} 
Junto a esto, encontramos que la poesía de Montejo no rehuye, sino por el contrario cultiva la reiteración de los mismos símbolos: piedras, gallos, café, luz, nieve, el trópico, etc. Esta economía de símbolos y temas le imprime a su obra un carácter estable, creando un espacio poético, delimitado y coherente, que lejos de agotarse en sí mismo posibilita la existencia de un sólido universo simbólico. Podrían ser muchos los ejemplos en este sentido; mencionemos tan sólo la figura de "Orfeo", la cual surge por primera vez en el poema que cierra Muerte y memoria, ${ }^{3}$ para aparecer luego en "Arqueologías" de Terredad, en "En esta ciudad" de Trópico absoluto y por último en Alfabeto del mundo, bajo la forma de un "Orfeo revisitado", donde se hace uso del verbo "orfear":

Orfear, verbo que nos declina su alto sueño,
verbo en milagro del espíritu,
cuando tartamudeante y roto y solitario
paga en cantos su vida y jura a ciegas
que tras sus pasos un ángel musicante
va recogiendo los últimos sonidos.

El caso de Orfeo es sin duda uno de los más representativos de esta obra, ya que en él se conjugan tres elementos indisociables y presentes en toda ella: el símbolo como conjunción de tradiciones, el valor arquetípico, y la capacidad de recreación mítica que pervive en el texto. En esa dirección Montejo procede a elaborar el poema. Ante la aparente vigilia del homo rationalis, el concepto se hace símbolo. La piedra, el gallo, el café o el pájaro - seres y cosas de un orden elemental - se van sucediendo en un intento de volver a lo originario; a la imagen primigenia, latente en el espíritu fabulador que rige el poema. El poeta ejerce así una de las funciones primarias del lenguaje poético: "evocar imágenes, conjurar una realidad y hacerla preexistente, representativa $\mathrm{y}$, a su vez, describirla" ${ }^{4}$ Todo ello, circunscrito a un universo cultural, histórico y lingüístico muy específico.

Es claro que el símbolo en el texto poético, aunque surge de procedimientos metafóricos, es algo más que una metáfora. Lo que lo determina no es tanto su procedencia como su potencialidad significativa. Así podemos decir, con Wilbur Marshall Urban, que "la metáfora pasa a ser símbolo cuando por medio de ella encarnamos un contenido ideal que no puede expresarse de otra manera" (Serrano Poncela 116). Este es el carácter específico que tiene el símbolo como componente del lenguaje poético, y en el caso particular de la obra de Montejo como centro de irradiación del sentido, en tanto significación, del poema.

No es fortuito el uso constante que Montejo hace de toda una serie de símbolos que, apartados de su contexto original, van amplificando y enriqueciendo su significación;

\footnotetext{
${ }^{3}$ Es importante señalar que la primera mención crítica que hay sobre este poema la hace Ignacio Iribarren Borges. "Dos poetas y su revista" [hace referencia a la actuación de Montejo y Alejandro Oliveros en la revista Poesía, de la Universidad de Carabobo]. El Universal (Caracas, 17 de mayo de 1975).

${ }^{4}$ Segundo Serrano Poncela, Formas simbólicas de la imaginación (Caracas: Equinoccio, 1974) 115 .
} 
siempre en estrecha relación con aquellos otros que dialogan dentro de ese discurso poético. De esta forma, paulatinamente el lector va "descifrando" un sistema de símbolos que sirve como soporte y contexto de cada poema. Tal es el caso de la figura del "caballo", en su alianza con la imagen del "padre" y con el "viaje" vital, suerte de experiencia cíclica que brinda continuidad a la existencia. Así también, "el café" es un elemento que evoca una suerte de rito ancestral, en el que los seres del pasado se reunen junto a los vivos en torno a la mesa. "El pájaro" representa también una figura fundamental dentro de esta poética. El es el canto y la celebración vital, aquello que en su fugacidad se erige como permanencia. "El gallo" es otro símbolo polivalente y constante. En él se conjugan: la nostalgia provinciana, la voz que surge del conflicto entre el poeta y la modernidad, y esa especie de receptáculo del vacío, donde se aloja el canto matutino y la realidad más plena. Otro caso es el de "la piedra": "maestra amarga" de rasgos ambivalentes. Por un lado, sabiduría inmutable de lo que es y permanece, y por el otro, sostén de los muros opresores que erigen a la metrópoli desenfrenada.

Indudablemente son muchas y múltiples las resonancias que cada uno de estos símbolos, entre otros, tienen en este espacio poético. A ello se añade la dinámica propia de la obra, la cual se ve sometida, lectura tras lectura, a un proceso constante de reelaboración y reinterpretación.

Vale la pena subrayar otro aspecto que caracteriza la poesía de Montejo. Me refiero a la continua superposición, que encontramos en sus textos, entre dos planos distintos de lectura: el conceptual y el simbólico. Esto, que me parece una característica definitoria de su poesía, constituye uno de los ragos fundamentales de esta poética. Tomemos un ejemplo para ilustrarlo:

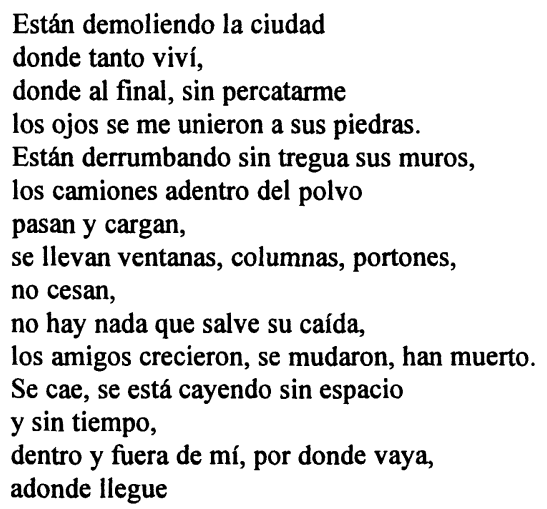

(“Están demoliendo la ciudad", Terredad)

El nivel de la anécdota no puede ser más simple, ni la imagen más gráfica: los camiones llevándose los escombros de los muros de alguna construcción que ha sido derrumbada para dar paso al crecimiento de la "metrópoli". Sin embargo, ese hecho aparentemente externo comienza a adquirir una dimensión simbólica. Nos encontramos ante un proceso de amplificación del sentido del texto que, apoyado en elementos muy concretos como el 
camión, el polvo, ventanales, columnas y portones, logra enunciar una experiencia sensible profunda, en la que entran en juego múltiples niveles de evocación ligados al recuerdo, la infancia, la familia, la ciudad o la casa. Así, esos "camiones dentro del polvo" pasan a formar parte de una realidad anímica mucho más compleja, en la que se habla de la caída, ya no de muros, sino del tiempo y del espacio. De esta manera, el texto como totalidad adquiere un espesor simbólico, que se sobrepone al aparente carácter discursivo.

Una categoría que quizás nos permite aproximarnos, con más precisión, a la utilización de este procedimiento, recurrente en la poesía de Montejo, es la apuntada por T. S. Eliot al estudiar el Hamlet ${ }^{5}$ de Shakespeare; me estoy refiriendo a lo que él llamó el objective correlative. Idea que en su oportunidad expresó en los siguientes términos:

The only way of expressing emotion in the form of art is by finding an "objective correlative"; in other words, a set of objects, a situation, a chain of events which shall be the formula of that particular emotion; such that when the external facts, which must terminate in sensory experience, are given, the emotion is inmediately evoked. ${ }^{6}$

En efecto, es a partir de ese "conjunto de objetos" y de "hechos externos" que conforman una determinada situación enunciativa, que la emoción poética logra ser evocada, alcanzando el poeta plasmar la "experiencia sensible" en el poema. Así, el símbolo en Montejo - y aquí hablo de la función simbólica de ese "correlativo objetivo"- no asume el carácter autárquico que Hugo Friedrich le ha asignado dentro de la lírica moderna ${ }^{7}$ sino que se corresponde con una función de permanente vigilia y búsqueda de coherencia en la construcción del poema y de la obra como un todo. Por otra parte, aunque la procedencia de los símbolos empleados por Montejo no corresponde a un "patrimonio común de la poesía" previamente codificado (como sí ocurrió en cierta medida hasta la poesía romántica), éstos poseen una significación que aunque estrechamente ligada con el desarrollo muy particular de este espacio poético no niega su deuda con la tradición. No debemos olvidar que para Montejo "la modernidad en cualquier época la constituye el modo distinto y específico de prolongar una tradición, de formular desde ángulos inéditos su relectura" (Montejo, El taller 27).

De nuevo, vale recordar lo dicho por Eliot: "toda obra nueva mueve a las demás, pasadas, presentes y futuras". Borges también insistía en que toda obra y en particular todo poema, era una relectura y una reelaboración de la tradición y de los eternos temas que acompañan al hombre. En el caso de Montejo sabemos que no son pocos los poemas que cumplen ese cometido. Es en la relectura y en la reelaboración de los "eternos" temas (la muerte, la vida, el tiempo, el deseo, etc.) que su poesía halla centro. Por otra parte, tampoco son escasas las referencias - no siempre oblicuas- a otros poetas y artistas. Algunos casos son: Li Po, en "Partida" de Terredad, Cavafy, en los poemas "Ítaca" y

\footnotetext{
${ }^{5}$ Por cierto, resulta curioso observar que este personaje es una de las figuras literarias que aparece con mayor frecuencia en la poesía de Montejo. De él se hace mención en cuatro poemas: "Hamlet acto primero" (Muerte y memoria), "La torre del árbol" (Trópico absoluto), "Santo y seña" (Alfabeto del mundo) y "Las ranas" (Alfabeto del mundo).

${ }^{6}$ Selected Prose of T. S. Eliot (London: Faber \& Faber, 1986) 48.

${ }^{7}$ Hugo Friedrich, Estructura de la lírica moderna (Barcelona: Seix Barral, 1974) 216.
} 
"Ulises" de Alfabeto del mundo, Pessoa, en otro poema del mismo libro, Saba en "Trieste" y Supervielle en "Noches de trasatlántico" de Adiós al siglo XX. Sin embargo lo importante es resaltar cómo ello induce a una aproximación distinta, por parte del lector, tanto a la obra de los poetas y artístas allí aludidos, como a la obra del propio Montejo, pues ella ha hecho en gran parte su materia de la relectura de esa tradición poética. En ello radica la función que Montejo le atribuye al poema, como punto de encuentro: conjunción y diálogo entre el arte como universo simbólico y la realidad de la que éste se desprende.

\section{B. LA MODERNIDAD, EL POETA Y EL POEMA}

Hablar de "modernidad" en el ámbito poético no es una discusión fácil ni reciente. Ya a mediados de la segunda mitad del siglo pasado el autor de Une Saison en enfer, ${ }^{8}$ en el poema "Adiós" nos advertía, en relación al poema: "es necesario ser absolutamente moderno". Un siglo después Wallace Stevens manifiestaba todo lo contrario: "no se puede perder el tiempo en ser moderno cuando hay tantas cosas importantes que ser".? Entre estos dos polos y tras una larga secuencia de "ismos" se ha erigido la literatura moderna y en particular la poesía contemporánea. La poesía de Montejo tampoco escapa a tal disyuntiva, presentándose como un poeta que ve en la modernidad no una ruptura con el pasado sino, por el contrario, un intento de "relectura de la tradición". Y al hablar de tradición estoy hablando también de un idioma, esa materia viva con la cual trabaja el poeta. Recordemos que Borges decía: "Un idioma es una tradición, un modo de sentir la realidad, no un arbitrario repertorio de símbolos". ${ }^{10}$ Es así como el caso de Montejo se podría emparentar con el de poetas como Salinas, Guillén, Umberto Saba, Supervielle o el Borges posterior al período ultraísta. Constructores todos ellos de sólidos espacio poéticos, quienes alejados del influjo de las tentaciones vanguardistas, supieron hacerse de toda una vasta tradición poética sin rehuir su realidad histórica y cultural.

Quizás valga la pena citar las palabras de Mario Luzi en relación con la obra de Umberto Saba, por ser ellas lo suficientemente elocuentes para abordar el tema de lo "moderno" en la poesía y en los poetas:

La poesía de Saba se diferencia de cualquier otra poesía moderna. Ante todo, no parece ser una poesía inventada (el "shock" de la invención, de la hipótesis, de la asociación de imágenes, le es extraño) sino que más bien se revela como una poesía íntimamente vivida y a la vez recurrente, como en un ciclo inagotable ... Quizás sea preciso esperar que el mito de la modernidad, introducido en la poesía a través de Baudelaire y afianzado por Rimbaud, se agote completamente para leer de manera adecuada, a un autor que en verdad y no arbitrariamente trató de fundir y disolver ese mismo mito. ... apartó de su poesía, repito, la euforia pero también la humillación de llamarse moderna, porque "moderno" es, realmente, un término limitante. ${ }^{11}$

\footnotetext{
${ }^{8}$ Authur Rimbaud, Une Saison en enfer (1873).

${ }^{9}$ Wallace Stevens, Adagia. Traducción Guillermo Sucre (Caracas: Fundarte, 1977) 26.

${ }^{10}$ Jorge Luis Borges, Obras completas (Buenos Aires: Emecé Editores, 1974) 1081.

${ }^{11}$ Mario Luzi, Discurso naturale (Milano: Garzanti Editore, 1984) 57-58. Contenido en Umberto Saba, El cancionero. Traducción Ana María del Re (Caracas: Monte Ávila, 1990).
} 
Recordemos, por un momento, las características de la poesía moderna - aquélla que se inaugura a partir de Baudelaire- que Hugo Friedrich destaca en su libro la Estructura de la lírica moderna (1956):

\begin{abstract}
Ausencia de una lírica de sentimiento e inspiración, imaginación guiada por el intelecto, destrucción de la realidad y del orden lógico y afectivo normal, manejo de las fuerzas impulsivas del lenguaje, substitución de la inteligibilidad por la sugestión; conciencia de pertenecer a una época tardía de la cultura, doble actitud frente a la modernidad, ruptura con la tradición humanística y cristiana, aislamiento con conciencia de superioridad, y equiparación de la poesía con la crítica poética, en la que predominan, por lo demás, las categorías negativas (Friedrich 125).
\end{abstract}

Pues bien, si por "moderna" entendemos sólo aquella poesía que comparte los postulados expuestos, nos encontramos con que una obra como la de Montejo poco tiene que decir al lector contemporáneo. Se hace evidente que el problema es más complejo. ¿Qué es entonces lo que define la contemporaneidad de un poeta? Creo que en ello tiene mucho que ver la autenticidad de su palabra, la cercanía con su realidad, y el reto de asumir esa doble confrontación que impone el tiempo: tanto al poeta, en su circunstancia vital, como al poema, que aspira perdurar más allá del tiempo de su creación. Mairena decía: "La poesía es el diálogo de un hombre, de un hombre con su tiempo", para luego añadir, con su ironía y lucidez característica: "El poeta es un pescador, no de peces, sino de pescados vivos: entendámonos: de peces que pueden vivir después de pescados". ${ }^{12}$ Sobre este punto, el mismo Montejo ha reflexionado al advertir el peligro que las modas y las estéticas, amparadas en una pretendida modernidad que sólo se detiene en los aspectos más superficiales, imponen en la consecución del poema:

Las palabras se someten en el juego de la estética a oscuras leyes de fluctuación que alzan o devalúan su prestigio a los ojos de quienes de ellas se sirven. Nada más azaroso que estos cambios de valores, obedientes a mutaciones de los tiempos y cambios del espíritu ... En esta mecánica de los contra todo escrito vive a merced de lo que calla. El poeta elude lo manido para captar otros contenidos emocionales. Su modernidad le viene por lo que detecta y esquiva, por la carta que oculta en su diálogo con las musas (Montejo, La ventana 55).

Consciente de ese reto, Montejo opta por una propuesta poética que se muestra vigilante ante ciertos arrebatos verbales y malabarismos formales que lejos de aportar hallazgos verdaderos se resquebrajan ante la mirada del tiempo. Tomemos un ejemplo que nos permita aclarar esto. Hagamos referencia a lo que Friedrich llama la "lírica de sentimiento". Sobre ella, Rimbaud decía: "Mi superioridad consiste en que no tengo corazón", a lo cual Gottfried Benn pareciera añadir: “¿Sentimientos? Yo no tengo sentimientos”. Esta actitud, común en buena parte de la poesía contemporánea, no puede ser más opuesta a la de Montejo, quien ve en el sentir — sin que ello se confunda con una actitud ingenuamente romántica - la matriz germinal del poeta y del poema:

\footnotetext{
${ }^{12}$ Antonio Machado, Juan de Mairena. Sentencias, donaires, apuntes y recuerdos de un profesor apócrifo (1936; Madrid: Clásicos Castalia, 1971) 80.
} 
Aprender a sentir: esta sola tentativa, que no es nada pequeña, formaría mejor al joven poeta que todo el aprendizaje perseguido a través del conocimiento literario, las reglas, las modas, etc. Los manuales olvidan con frecuencia esta simple realidad, sin la cual todo intento creativo queda en el aire. A través del sentir puede válidamente conquistarse el lenguaje que lo exprese; el sentimiento mismo, cuando es legítimo, procrea su forma o la posibilidad de inventarla. Lo contrario, en cambio, es menos probable. ¿Cómo bajar de la red formal a la desnudez sentimental del mundo?

Pero es necesario aclararlo. Cuando Montejo habla del sentimiento, no predica la anulación de la razón ni del intelecto, como actividades antagónicas al sentir; muy por el contrario, su intento va en busca de alcanzar un adecuado proceso intelectivo, que sirva de guía y que a la vez asegure la presencia de ese sentir en el poema. Tampoco debemos confundir lo que se propone, con el fácil recurso de la sentimentalidad ("La sentimentalidad es un fracaso del sentimiento", advertía Wallace Stevens (Stevens 11)), su tentativa va en otra dirección: encontrar en la emoción el sustrato del arte.

Pero hay un elemento más. Me refiero a la capacidad del poema como portador de una experiencia colectiva, en la que el poeta es capaz de transmitir, a través de su obra, una emoción y una vivencia que va más allá del ámbito personal. Sobre ello, el mismo Machado decía:

La poesía lírica se engendra siempre en la zona central de nuestra psique, que es la del sentimiento; no hay lírica que no sea sentimental. Pero el sentimiento ha de tener tanto de individual como de genérico, porque aunque no existe un corazón en general, que sienta por todos, sino que cada hombre lleva el suyo y siente con él, todo sentimiento se orienta hacia valores universales o que pretenden serlo. Cuando el sentimiento acorta su radio y no trasciende del Yo aislado, acotado, vedado al projimo, acaba por empobrecerse $y$, al fin canta de falsete. ${ }^{13}$

A la par que el sentimiento, Montejo busca emparentar el poema con la vida. "No nos pidas más forma que la vida", nos dice en su "Epístola sin forma" recordándonos en esto a Vallejo, quien afirmaba: "antes que el arte la vida". En efecto, para Montejo la poesía es producto de la experiencia vivida. Pero ante todo reelaboración y enriquecimiento de esa experiencia, para hacerla más plena y vigente. Nada más contrario a la estética de Montejo, que el sentido de "modernidad" propuesto por Mallarmé, quien veía en el poeta a ese ser impersonal que trabajaba sobre la fórmula de un espíritu poético como "centro vibratorio de suspensión", y para quien la poesía, convertida en un meticuloso laboratorio de ordenar palabras, alcanzaba su fin al crear "una voz que ocultaba al poeta no menos que al lector", eliminando "al señor que quedaba al escribirla". Es evidente que la intención de Montejo es otra. Por ello, al referirse a la búsqueda de la"forma pura", en relación a la obra de Benn, afirma:

El vacío de la forma no se encarna nunca por un riesgo menor. Así, atrapada en la entelequia de visiones que postergaron la urgente presencia de lo humano, su palabra nos dice lo que el lujo verbal no podrá nunca arrebatar a la vida (Montejo, La ventana 50$51)$.

${ }^{13}$ Tomado de Ludovico Silva, Ensayos sobre Vicente Gerbasi (Caracas: Fundarte, 1985) 25. 
De ese contacto con la vida, tantas veces celebrada en su poesía, surge la palabra que importa a Montejo. El poema se convierte en forma de acción y conocimiento, al confrontarse con la realidad, esa que es esencial al poeta y que ha llamado "terredad". El misterio de las cosas habla así, a través de una poesía que aunque permanentemente anhela el silencio, no cesa de indagar en la "porosidad" de las cosas. Poesía que habla de (y a) la realidad.

Quizás Montejo sea ante todo un fabulador, pero un fabulador de la realidad. Ese "falso mago de bosques invisibles" como él mismo se definiría en un poema, es quien hace de las metáforas pensamientos. En su obra, la imagen no surge con pretensiones de instaurarse autónomamente sobre la realidad, sino que por el contrario, lo que la rige es el deseo de indagar en ella. Su proceder es el del poeta que cuenta cantando, a la manera de Orfeo, sin olvidar que el concepto y la imagen entrañan un secreto pacto. Blas Coll nos dice: "la lógica sirve a la realidad tanto como la geometría a las nubes". Sin embargo ¿cuánto no hay de conceptual en una sentencia como ésa? La escritura cautelosa, insomne ante la lámpara, sabe - como diría Valéry - que "quien quiera escribir un sueño ha de estar completamente despierto".

El poema aparece así como un arriesgado mecanismo que constantemente reta el equilibrio. El trabajo artesanal une cada una de las piezas, recurriendo a "las palabras más simples y necesarias, las de anónima cotización" (Montejo, La ventana 58). Montejo ha dicho a propósito de Supervielle, que fue un poeta que se negó a escribir para "especialistas del misterio"; agregando además: "Si la poesía tiene en su raíz una honda necesidad de sueño para oponerse al plano focal de la conciencia, el arte de Supervielle resuelve este deseo en una gran armonía con el mundo" (Montejo, La ventana 58). Si tales afirmaciones lucen ciertas para el caso del poeta franco-uruguayo, no son menos válidas en relación con la poesía de Montejo. Es ante todo una posición ética y estética lo que resguarda su valor. La técnica asumida desde una moral, desde una palabra que busca ser auténtica expresión de vida y permanencia.

Como orfebre y artesano, el poeta intenta acercarse al mundo, asumiendo la palabra desde tres perspectivas: 1) como parte indivisible de la realidad, 2) como traductora de esa realidad y 3) como evocación del silencio. Estas tres actitudes, que en el fondo se funden en una común aspiración: alcanzar la plena armonía con la Tierra y su misterio, son tentativas que permanentemente se superponen en la obra de Montejo.

\section{El poema como espacio Religioso}

"Hablar de Dios en voz alta ya no es hablar de Dios". Esto dice Montejo en uno de sus ensayos (Montejo, La ventana 9). Creo que allí se encuentra la intersección de dos actitudes consustanciales a esta poesía: la concepción del poema como espacio religioso y la palabra como evocación del silencio. Recordemos que para Montejo la poesía es la "palabra visitada por el silencio". ${ }^{14}$ Dios y silencio se emparentan como revelaciones de

${ }^{14}$ Eugenio Montejo, “Textos para una meditación sobre lo poético”, Zona Franca III/39 (Caracas, 1966) 20. 
un estado "absoluto". Pero también, gracias a la palabra, Dios y poeta se hacen rivales. Ambos, desde el verbo, son constructores de mundos. El acto de hablar que define al hombre, lo hace a su vez rival del Creador. El poema se convierte en el puente, a través del cual Dios y el poeta dialogan, como mediadores entre el silencio y la palabra. La escritura juega un doble rol, acto de profanación (violación del silencio) y comunión (vínculo con la experiencia religiosa). "Entre la catedral y las ruinas paganas", decía Rubén Darío, se mueve el poeta tratando de crear ese espacio otro que escape de la esfera de lo profano, del universo codificado que le rodea. Es esta la religiosidad que aspira alcanzar el poeta a través del poema. Religiosidad asumida, en su acepción más elemental y también más olvidada: como manifestación de algo superior e indecible. En efecto, etimológicamente esta palabra está vinculada al verbo latino religare: volver a atar, vincular de nuevo. ¿No es ésta la experiencia a la que se refiere Montejo?

Sabemos que el poema es forma cargada de sentido, sin embargo tras esta alianza lo que se esconde es un pacto mayor: el decir de lo inefable, donde forma y contenido se hacen indisociables. El poema, en tanto forma y lenguaje, se hace reducto de la experiencia religiosa desde el mismo momento en que su poder de significación trasciende, se hace manifestación, revelación de algo que va más allá de la pura verbalidad. De esta suerte, la escritura se convierte en rito celebratorio de ese oficio que consiste en hacer el poema (reiterándose una vez más, por su carácter ordenador —combinatoria de palabras- su parentesco con la figura de Dios). Pero más que combinatoria, para Montejo el poema es convocatoria. Por eso dice: "para que Dios exista un poco más/ - a pesar de sí mismo/ .../ los poetas en vela hasta muy tarde/ se aferran a viejos cuadernos". De esta forma, el poema pasa a ser el punto de elaboración de una teología personal —-cosa que él mismo atribuye a Supervielle - en que la creencia y no Dios es el punto focal.

Ya sabemos, que esta permutación en el acento de lo sagrado, donde la necesidad de creer se superpone al objeto de dicho credo, tiene su origen en el inicio mismo de la modernidad. Después de todo, "la muerte de Dios" es una idea que ha signado toda nuestra era. Montejo tampoco escapa al hecho de pertenecer a un tiempo donde el escepticismo como realidad reinante ha creado, paradójicamente, una insaciable necesidad de crear espacios espirituales propios. Para él, el poema es uno ellos. Y la poesía en nuestros tiempos, como diría Paz: "negación de la religión: pasión por la religión". ${ }^{15}$

Novalis entendía la religión como "poesía práctica" y la poesía como "la religión original de la humanidad". En efecto, durante un largo trecho de la historia de la humanidad la religión fue un fenómeno asociado al lenguaje, y la literatura, una experiencia religiosa. Para los antiguos la "forma perfecta" era una manifestación de sacralidad. ${ }^{16}$ Incluso la significación que algunos escritores latinos daban al adjetivo religiosus era la de "cuidadoso, preocupado por los detalles y la perfección" (Silva 33). Atento al cuidado de la forma, Montejo elabora el poema como un mecanismo en el que hasta "los más mínimos resortes deben hallarse en su sitio" para que éste "se ponga en movimiento".

\footnotetext{
${ }^{15}$ Octavio Paz, Los hijos del limo (Barcelona: Seix Barral, 1974) 70.

${ }^{16}$ Véase Mircea Eliade, Tratado de historia de las religiones (México: Ediciones Era, 1972) 35.
} 


\section{MONTEJO Y LA ESCRITURA HETERONÍMICA}

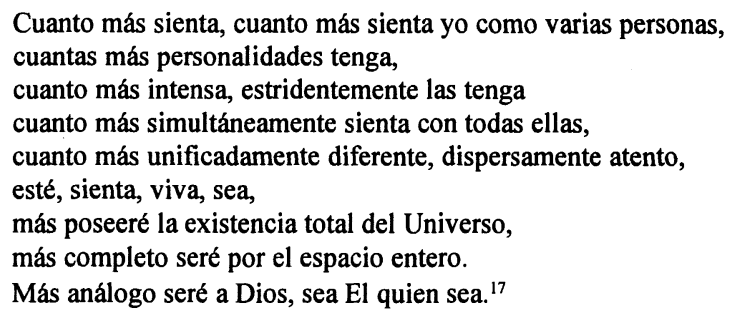

¿Acaso la práctica heteronímica, la creación de "miradas oblicuas" que le permitan abordar la realidad desde múltiples ángulos, es otra forma de vincularse con Dios y lo sagrado? Si bien, en el caso de Pessoa esto pudo ser así, en la poesía de Montejo la heteronimia es ajena a la búsqueda de Dios o al sentido religioso del poema. Ciertamente, es notoria la simpatía que Montejo tiene por este tipo de práctica escritural. Y aunque tan sólo ha publicado dos libros de heterónimos, ${ }^{18}$ no se puede obviar la presencia en su poesía de "esos otros" que lo habitan. Por lo demás, el mismo Montejo ha mencionado la existencia de algunos heterónimos, como Luis Cervantes, Tomás Linden y Eduardo Polo, que aguardan por ser editados.

En su obra ensayística podemos encontrar varias alusiones a este tema. Destaquemos algunas observaciones hechas en uno de sus trabajos, titulado "Los emisarios de la escritura oblicua". ${ }^{19}$ Allí, Montejo comienza relatándonos una extraña experiencia vivida por Rilke en el castillo de Berg, en la cual el célebre poeta se encontró inexplicablemente repitiendo unos versos que le venían a la mente y "no recordaba haber leído antes"; versos que halló luego en un viejo manuscrito que el conde C.W., "un afantasmado huésped del viejo castillo", leía junto a él, sentado a un lado de la chimenea. De esta extraña y breve historia se sirve Montejo como antesala para señalar el caso de diversos escritores contemporáneos que han dado lugar en su escritura a "voces oblicuas". Montejo hace referencia a casos como el de Aufzeichnungen des Malte Laurids Brigge de Rilke, A. O. Barnabooth de Valéry Larbaud, La Soirée avec Monsieur Teste de Paul Valéry, Juan de Mairena de Antonio Machado, Werf Rone de Gottfried Benn o las múltiples voces de Pessoa. Todos ellos, e incluso el mismo Montejo, han sido "víctimas" de la llamada de dichos emisarios en su escritura. Vale decir también que Montejo ve en esta práctica un fenómeno relacionado con el inicio de la modernidad (lo cual es interesante, atendiendo a la noción que tiene Montejo de lo "moderno" en relación a la poesía). De ello destaca algunos hechos que a su entender juegan un rol importante en la proliferación de tal tipo de escritura, como son: la aparición del cine mudo y el mundo de sonambulismo propiciado por sus rápidas imágenes; el triunfo de la estética cubista, movimiento que distingue por "la indagación simultánea

\footnotetext{
${ }^{17}$ Eugenio Montejo, El poeta es un fingidor (Antología poética). Traducción, selección, introducción y notas de Ángel Crespo (Madrid: Espasa-Calpe, 1982) 303.

${ }^{18}$ El cuaderno de Blas Coll (Blas Coll) y Guitarra del horizonte (Sergio Sandoval).

${ }^{19}$ Revista Nacional de Cultura L/274 (Caracas, 1989) 36-43.
} 
de la realidad plástica desde zonas hasta entonces no resaltadas por la imaginación"; la divulgación de la teoría de la relatividad de Einstein y las investigaciones psicoanalíticas emprendidas por Freud. Todos, en su opinión, fenómenos que ayudaron a establecer las fronteras con la visión de mundo y el modo de pensar que reinaron hasta finales del XIX.

Es claro por tanto que hablar de heteronimia en una obra como la de Montejo es un hecho inevitable - y cada vez con mayor razón - si tomamos en cuenta los indicios que se hallan en sus escritos. Esta característica, lejos de ser un rasgo añadido a su obra, se va convirtiendo lentamente en sustrato de ella. La heteronimia para Montejo, o la escritura de esas "voces oblicuas", como él prefiere llamarlas, no es simplemente una moda literaria. Dicha práctica responde a un modo de ver la realidad y sobre todo de verse en ella, pues a partir de esas múltiples miradas el poeta logra completar el abanico de sus visiones, dándole salida a formas y temas que con frecuencia se hallarían en contradicción con los postulados de su "identidad". Esas "voces oblicuas", surgen así como reflejo de una necesidad expresiva que paradójicamente, en lugar de enmascarar, descubren un cúmulo de miradas. $\mathrm{O}$, como diría Eustaquio Barjau, son una forma de: "librarnos de una cara con la que estábamos excesivamente avenidos y que se había convertido en máscara". ${ }^{20}$

En el caso de Montejo, la heteronimia más que una técnica se concibe como un modo de pensar y de relacionarse con el mundo. La ironía, el humor, ciertas formas clásicas o extravagantes, populares o infantiles pueden hallar en ella una manera de adquirir corporeidad, sin que ello atente contra la unidad de la obra del poeta creador de heterónimos. Machado decía: "antes de escribir un poema conviene imaginar el poeta capaz de escribirlo". ${ }^{21}$ Entonces la expresión literaria se convierte en una creación de segundo grado, en que siempre el paso previo sería la creación del poeta portador de esa obra. De esta manera, dicha gradación lo que refleja en definitiva es la búsqueda de un solo poeta (el ortónimo), que se hace eco en varios, a través de diversas instancias del proceso creativo. Más que de fragmentación, de lo que se trata es dar salida a la totalidad del pensar, a las distintas miradas que conforman el mundo subjetivo del poeta. Mairena, se preguntaba también: "¿pensáis que un hombre no puede llevar dentro de sí más de un poeta? Lo dificil sería lo contrario, que no llevara más que uno" (Machado, Obras 420).

Montejo parece entender su relación con la escritura de esta manera. Por tanto, su vínculo con la palabra no pretende únicamente llenar los espacios otorgados por el silencio. Va más allá: su tarea consiste también en dar cabida a las múltiples voces que lo acompañan.

\footnotetext{
${ }^{20}$ Eustaquio Barjau, Antonio Machado: teoría y práctica del apócrifo (Barcelona: Editorial Ariel, 1975).

${ }^{21}$ Antonio Machado, Obras. Poesía y prosa (Buenos Aires: Losada, 1964) 419.
} 